\title{
SATURN I FLIGHT TEST EVALUATION
}

by

F. A. SPEER

National Aeronautics \& Space Administration

Hunt sville, Alabama

AIAA Paper

No. 64-322 


\title{
SATURN I FLIGHT TEST EVALUATION
}

\author{
Dr. F. A. Speer \\ Chief, Flight Evaluation and Operations Studies Division \\ Aero-Astrodynamics Laboratory \\ George C. Marshall Space Flight Center \\ Huntsville, Alabama
}

\section{Introduction}

As this paper is being written, the Saturn I flight test program includes five flights launched between October, 1961 and January, 1964. A11 five fiights were complete successes, both in achieving all major test missions and in obtaining an unprecedented volume of system performance data for flight analysis. A conservative rough estimate of the amount of information received from these five flights is in the order of 550 million bits. This huge volume of data, consisting of telemetry, tracking, meteorological and acoustic data, films, and other point to a significant problem for the space vehicle development team: the timely and complete engineering evaluation of each individual flight. Timeliness and completeness are the keys to the success of any flight test program being primarily measured by its effect on the vehicle under development and the underlying design principles which extend to future vehicle generations.

It is the purpose of this paper to show, in a very condensed form, a representative cross section of the major Saturn I flight test achievements. Although the value of these flights cannot be adequately shown in a few system performance graphs, the illustrations given in this paper are considered indicative of the type of information which is being compiled now and utilized in designing and building the two major NASA Launch Vehicles of the future: the Saturn IB and the Saturn V.

Before showing the major Saturn I flight results, it appears appropriate to discuss briefly the R\&D flight test program and explain the resources available for flight testing.

\section{Saturn I R\&D F1ight Test Program*}

\section{2.a. General}

The Saturn I R\&D flight test program consists of ten vehicles, divided into four one-stage Block I flights and six two-stage Block II flights. Except for the first (SA-5), all Block II vehicles will carry an Apollo Boilerplate capsule in preparation for Saturn IB-Apollo missions to be initiated in 1966 .

The flight tests are the culmination of an elaborate ground test program. Before each individual vehicle or a series of similar vehicles is committed to a flight test, there are a number of specific ground tests which must be passed. The general advantage of ground tests being, of course, the isolation of subsystems to be tested, the possibility of unrestrained monitoring, and the examination of the test item after the test has been performed. These tests increase the confidence factor of mission success and are considered very important in lowering the risk of damage to the very expensive launch facilities.

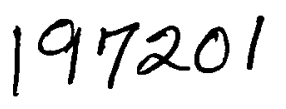

The Saturn launch vehicle, by its thrust and payload capability, constitutes a new class of space vehicles designed to lift large manned spacecraft into earth orbit. The increased size and complexity resulted in very high cost per single launch. The obvious consequence of such high cost is an attempt to reduce the number of test flights set aside primarily for vehicle development.

In recognition of these constraints the test engineer has two possibilities to compensate for the loss of additional test flights, i.e. (1) to increase the number and validity of ground tests, and (2) to increase the level of inflight measuring instrumentation. With regard to the second possibility, it is interesting to note in Figure 1 how closely these two factors, total number of R\&D flights and number of telemetered measurements per flight, are correlated.

The consequences of these trends are twofold. There is first a heavy burden on the instrumentation and $R F$ systems engineer to accommodate all requested information gathering systems and to provide for accurate transmission. Secondly, the flight analysts face an unprecedented deluge of all kinds of data waiting to be analyzed within the relatively short times left between the scheduled launches. This calls for a well organized flight evaluation effort of a great number of people and adequate facilities for large scale data processing.

\section{2.b. Vehicle Description}

Figure 2 and Table 1 show the major characteristics of Saturn I SA-5, the first of the Block II vehicles. The vehicle is 164 feet long, 21 feet at the largest diameter, and weighs approximately $1,130,000$ pounds at liftoff. Eight tail fins (four large and four stubs) on the S-I stage provide support and hold-down points for launch and, under certain conditions, aerodynamic stability during flight.

Eight liquid-fueled Rocketdyne $\mathrm{H}-1$ engines, each developing 188,000 pounds of thrust, power the S-I stage. The four outboard engines are gimbal-mounted for directional control. Six liquid hydrogen/liquid oxygen Pratt and Whitney RLlOA-3 engines power the S-IV stage. All six engines are canted outboard six degrees and gimbal-mounted.

The S-I stage attaches to the S-IV stage through the S-IV aft interstage. The aft interstage is bolted to the spider beam of the S-I stage. S-I/S-IV separation occurs between the S-IV aft skirt and S-IV aft interstage.

A 154-inch diameter, 58-inch high, $\mathrm{GN}_{2}-$ pressurized, instrument unit is located between the forward S-IV interstage and the payload adapter assembly. The instrument unit houses the vehicle control system, a developmental guidance and control system, tracking systems, and power supplies.
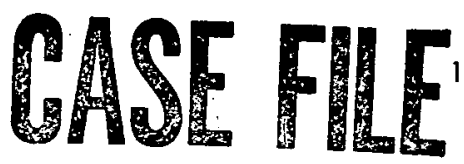
Approximately 1,180 measurements throughout the vehicle are monitored during prelaunch and flight in order to obtain sufficient information to adequately evaluate the vehicle performance.

The orbital payload capability of this R\&D flight was approximate $1 \mathrm{y} 18,000 \mathrm{lb}$, the total weight of the orbiting body being $38,3001 \mathrm{~b}$.

\section{2.c. Launch Complex LC 37}

The launch pad facility shown in Figure 3 includes the launch pedestal, supporting structure, and rail-mounted jetstream deflector. The launch pedestal is 42 feet high and stands in the center of the launch pad. The umbilical tower is adjacent to the launch pedestal and is used to provide electrical, hydraulic, and pneumatic service to the vehicle. Swing arms provide service connections at the various service points on the vehicle.

The blockhouse includes equipment and instrumentation to monitor, control, and correct the operation of the ground support $t_{\text {, }}$ and vehicle systems. It is the central coordinating point of these systems and assures proper sequencing and control of the launch functions.

The Vehicle Launch Facility $37 \mathrm{~B}$ is constructed for a $90^{\circ}$ launch azimuth. A roll maneuver, which was initiated eight seconds after liftoff and terminated approximately five seconds later, rotated the vehicle $\mathrm{SA}-5$ to a $105^{\circ}$ flight azimuth.

\section{2.d. Test Objectives}

The fundamental mission of a11 Saturn I test flights is to prove the launch vehicle design and advance the state of the art in booster technology. Regardless of the very impressive payload capability, the real "payload" of the ten scheduled Saturn I flights consists of knowledge, flight experience, and design confidence. These factors will be reflected in the advanced designs of the Saturn IB and Saturn V launch vehicles.

To be more specific, the first four one-stage flights served primarily to test the eight engine cluster propulsion system, the clustered tank structure, the first stage control system coping with sloshing and non-rigid body dynamics, and finally the compatibility between vehicle and launch facility.

As shown in Table 2, these five test objectives were primary for all Block I flights. In addition, there was a balanced and systematic buildup of test missions preparing the way for the first full two stage flight, SA-5. Starting with the third flight, SA-3, cutoff was initiated by LOX depletion rather than by timer to obtain highest possible performance. Retro rockets were tested for impulse, alignment and effect on RF transmission. Advanced umbilical swing arm connections were also tested on both the third and fourth flights. The heat protection material on the base of the vehicle was gradually replaced by the final ceramic material selected for Saturn $I$. On each flight, there was also an increasing amount of passenger guidance equipment flown in the true environment of the ascending launch vehicle. The third flight had provisions for full Block II propellant loading, testing the effects of long powered flight duration, and low liftoff acceleration. On the fourth flight, three additional important steps toward the Block II configuration were taken. The former angle of attack control sensors for attitude stabilization were replaced by accelerometers after preceding passenger tests had proven that their location would yield satisfactory results. Next, a simulation of all major Block II aerodynamic protuberances such as fairings, vent ducts, and ullage rockets was performed to gain insight into any resulting unsteady aerodynamic loads. Finally, new antenna designs were tested identical to those flown on Block II vehicles.

Besides these straight development missions, there were a few interesting experiments. The most important was a deliberate single engine-out command given by timer 13 seconds prior to normal cutoff. This happened on the fourth flight, SA-4, to check the feasibility of completing the flight mission even after failure of a major sybsystem. Perhaps somewhat exotic were two experiments conducted on the second and third flight releasing $190,0001 \mathrm{~b}$ of water contained in the upper dummy stages at very high altitudes and studying, from the ground, the various mechanical and chemical dynamics effects in the upper atmosphere resulting from this rather unusual injection.

As a culmination of the four preparatory flights, the fifth flight was the first to test separation, the Douglas-built second stage, and the $R \& D$ version of the Saturn I Instrument Unit. In addition, the $\mathrm{H}-1$ engines of the first stage propulsion system were uprated $14 \%$ to deliver $188,0001 \mathrm{~b}$ thrust each.

\section{2.e. Ground Test Program}

Ground tests are a vital prerequisite of any successful flight test program. Of special importance in this connection are Qualification Tests and Acceptance Tests, the former generally performed on non-flight items to qualify the final design of subsystems, the latter performed to accept the vehicle systems for flight testing.

Table 3 shows a simplified breakdown of these two test categories into major items of interest. It should be noted that a large amount of hardware is involved in the Qualification Tests. GSE tests require a facility test vehicle, all systems static tests (captive firings) required a dynamic test vehicle. Most of these tests are common for a group of vehicles having basically the same configuration. However, significant changes in the configuration or mass distribution result in renewed dynamic tests where each flight stage is vertically suspended and excited in its bending modes.

The next step in the ground test program concerns the flight item itself and starts after assembly, approximately 16 months prior to launch. As shown in Table 3 there are four major milestones, the second being the most important one, a full duration captive firing of each of the two stages. These static tests are enclosed by thorough checkouts, the pre - and post-static tests. Averaging the Block I vehicle schedules, roughly $50 \%$ of the 16 months between start of assembly and launch are spent in vehicle assembly; $35 \%$ of the time is used for the group of static tests; during the remaining $15 \%$, or approximately 2 months, the vehicle stages 
are shipped to Cape Kennedy, are checked out, erected on the pad, and undergo final preflight tests. The corresponding figures for Block II vehicles differ only slightly from those on Block $\mathrm{I}$.

\section{F1ight Test Resources}

\section{3.a. Instrumentation}

There are four main factors which determine the trade-off characteristics of an optimum space vehicle R\&D instrumentation: (1) the number of R\&D flights available before the vehicle is committed to operational use; (2) the ratio of the cost of instrumentation to that of the vehicle; (3) the weight penalty incurred by instrumentation in relation to the payload capability; (4) the degree to which the overall vehicle performance is taxed by the anticipated payload requirements (high or low margin). In case of the two stage Saturn I this optimization leads to approximately 1,200 onboard measurements and a great number of ground measuring systems.

Tracking used for trajectory determination includes fixed cameras, theodolites, Azusa, UDOP, and Radar. A Mistram beacon was carried on a developmental basis. The addition of the second stage and the extended burning time of SA-5 resulted in an increase of $33 \%$ in number of tracking instruments from Block I to Block II flights.

Engineering sequential cameras were used to film the launch sequence with a wide variety of film speeds and materials. Eight recoverable cameras were used on SA-5 to view separation and other important functions.

Pad environmental measurements are vital for development and evaluation of the Saturn launch complexes.

Meteorological measurements serve the dual purpose of establishing launch criteria and defining the vehicle environment for post-flight analysis. The equipment now in use includes the standard rawinsonde measurements and high altitude rocketsonde flights.

Sound measurements are taken at various near and far field locations in the vicinity of the launch complex up to a distance of 15 miles. They are taken to predict and eventually control the generation of acoustic pressures during hold-down and ascent.

Blockhouse measurements are transmitted by hard wire to the Launch Control Center to monitor all vital vehicle functions through countdown and liftoff.

Telemeter ground stations are required in adequate numbers to cover the entire flight profile for the active life of the telemeter transmission from the vehicle. For SA-5, this extended beyond the cutoff point well into the first orbit.

The most important information sources are telemetered on-board measurements. As mentioned previously and demonstrated in Figure, the very high cost of each Saturn flight necessitated a rigorous reduction in number of vehicle $R \& D$ flight tests as compared with previous missile programs. In order to test the numerous flight techniques and hardware items incorporated in the comparatively few Saturn I vehicles to be flown, and as a consequence of increased vehicle size and complexity, the number of flight measurements increased as the program progressed.

Figure 4 depicts the number of inflight measurements for the first five Saturn launch vehicles. Four categories of measurements are shown in the figure. Three of these (environmental, propulsion, and flight dynamics) are fairly selfexplanatory; the fourth (other) included vibrations, bending accelerometers, signals, sequence steps, etc. There were 1180 measurements telemetered to the ground from SA-5, whereas an average of 560 were telemetered from Block I vehicles.

Data transmission for flight testing SA-5 was effected by 13 telemetry system links while Block I vehicles (SA-1 thru SA-4) utilized eight links.

In order to illustrate the tremendous output of information resulting from the Saturn flights, the information received has been broken down into bits of information from four major sources, telemetry, blockhouse and pad environment, tracking, and camera. Figure 5 shows a comparison of Block I and SA-5 data bits from the six major sources.

The amount of information displayed in Figure 5 clearly shows the magnitude of the flight evaluation task and points to the need for efficient data processing equipment and we 11 organized manpower utilization.

\section{3.b. Data Processing}

The use of data processing equipment for engineering flight evaluation at the Marshall Space Flight Center in Huntsville, Alabama, has expanded with the largely increased amount of space vehicle data.

In a broad sense, data processing includes not only the reduction of raw data to engineering units but also computational programs that simulate and reconstruct the actual flight by matching selected observations.

Table 4 shows the data processing equipment utilized on the first five Saturn flights and their reduction function. The reduction function shown is generalized and does not reflect all functions of each piece of equipment. Over 50 computer programs are in existence at MSFC for evaluating Saturn I flights. Operation of these programs is reflected in the machine hours shown in Table 4.

The function of the ground station is to convert magnetic tape input into oscillographs that represent a graphical record (non-linearized) of measured flight information as it was recorded at the ground receiving station.

The PCM station, through a synchronization process, makes serial-to-parallel conversion on pulse code modulated data. The RCC- 3 converts raw cycle information into digital values, and the microsadic makes analog-to-digital conversion of pulse amplitude modulated data and frequency modulated data. 
The IBM 1401 is used as auxiliary equipment for the $7090 / 7094$ and B-5000 input-output programs.

The IBM $7090 / 7094$ and B-5000 are the high speed work-horses for data processing. These computers are used to convert the counts or numbers from the PCM station, microsadic, and raw cycle counter into linearized data (final numerical form) by processing the digitized data into correct measuring units while utilizing additional input established from appropriate calibration curves. Linearized output from these machines is again processed in evaluation programs (trajectories, flight simulations, Fourier analysis, etc.) by re-submitting certain parameters to the machines from a collation program. The linearized data is also displayed by utilizing a Stromberg-Carlson SC-4020 plotter, microfilm printer-plotter system or an EAI (Electronics Associates, Inc.) versatile tape plotter.

Analog flight simulations of various types are performed on a $131 \mathrm{R}$ Electronics Associates Analog computer. Spectral density analyses of vibration measurements are obtained from a Tech Products Corporation Analog Computer.

The primary piece of optical equipment for engineering film reduction is a Mann Comparator.

\section{3.c. Flight Evaluation Manpower}

The total manpower requirement for the evaluation of a space vehicle is dependent on a number of factors. The primary factors determining manpower requirements are the complexity of the vehicle system (number of stages, amount of instrumentation, etc.), the extent or depth of ... evaluation, the efficiency of evaluation (experience, skill, and mechanization), and the frequency of launchings.

The basic concept of the MSFC engineering flight evaluation is to let the design development engineer evaluate his own system and to coordinate and integrate all individual efforts through a strong central organization, the Flight Evaluation Working Group. This concept implies full participation of the industrial team working with MSFC on the Saturn development. All stage and engine contractors are represented by their own Working Group members and/or flight evaluation liaison teams. The focal point for coordination and information exchange are regular evaluation meetings conducted in a special facility located in Huntsville, Alabama.

The total manpower utilized by all parties involved in SA-5 was approximately 120,000 manhours as shown in Figure 6 . In comparison, this was five times more than on Block $I$ vehicles and almost 10 times greater than on an average Jupiter missile evaluation. It is important to note that all flights used in this comparison were successful flights. Major malfunctions, on one hand, tend to increase the effort required if the source of the problem is not obvious - on the other hand, may decrease the effort due to premature termination of flight reducing the total amount of data received.

In general, the effort required for space vehicle flight evaluation is a direct function of the number of measurements to be evaluated and can be predicted on this basis for future flights with good accuracy.

The flight evaluation report may be considered the end product of the vehicle systems evaluation. Figure 7 shows the actual schedule and the milestones leading to the report publication.

\section{Flight Test Achievements}

4.a. Genera1

The more successful a flight test program is, the less obvious are the real achievements obtained through each single test. However, one must not only consider changes on the vehicle made as a consequence of test results as the true measure of achievement. The increased confidence in the vehicle design, proven reliability factors, and confirmed theoretical predictions are equally important. However, it is in fact difficult to reflect the total sum of our Saturn achievements by a handful of performance curves or a tabulation of modifications which have been initiated on the basis of the flight evaluation.

The post-flight analysis aims at establishing both the vehicle systems performance and the vehicle environment to a high degree of accuracy. Performance and environment are equally important in assessing the results and significance of any individual test flight.

Launch Operations - After vehicle erection on. the launch pad, approximately 8 to 10 weeks are necessary to assure that the vehicle, vehicle systems, and subsystems are ready for flight test: The final checkout is essentially completed 3 to 7 days prior to launch. Fuel is loaded on the vehicle two days prior to launch, and the countdown begins, one day prior to launch.

Countdown initiation to launch is normally scheduled for 17 hours and divided into two parts by a built-in hold after the first 7 hours. This split in the countdown is necessary to avoid launch crew fatigue. The final 10 hour countdown is usually extended due to holds. The countdown holds for each of the first five Saturn I's are shown in Figure 8 . The holds are categorized into either (1) due to vehicle and ground support equipment or (2) due to weather and range. The holds resulted from the following conditions:

(1) Vehicle/Ground Support Equipment Holds --A 45 minute hold was required on $\mathrm{SA}-3$ to replace a sensing device for a ground networks generator. A 40 minute hold occurred on $\mathrm{SA}-4$ to replace an alignment theodolite. At the same time, a fuse was replaced in one of the telemeter calibrators. Another ground support equipment hold lasting 42 minutes was required on $\mathrm{SA}-4$ because the position indication of the LoX bubbling valve was incorrect. A 20 minute hold was required on $\mathrm{SA}-4$ to evaluate an out-of-tolerance indication in the ST-90 stabilized platform. An attempt was made to launch SA-5 on January 27, 1964, but the launch was scrubbed because a test flange had not been removed in the S-I stage replenish line. The 95 minute total hold consisted of a 3 minute hold for network checks; a 17 minute hold for battery verification; a 27 minute hold to change an. 
accelerometer; and a 48 minute hold to repair a LOX leak in the LoX main fill topping control system.

(2) Weather and Range Holds -.- A 34 minute hold and a 32 minute hold were necessary on SA-1 to await more favorable cloud conditions necessary for photo coverage. A 30 minute hold was required on SA-2 to clear a ship from the downrange area. A 73 minute hold was required on $\mathrm{SA}-5$ to correct $\mathrm{RF}$ interference in the range area.

At $T$ minus 6 minutes, automatic countdown begins; it was normal for all flights. A few minor deviations were detected and corrective measures were taken. Compatability between the ground support equipment and the vehicle has been very satisfactory during launch of all Saturn vehicles.

Critical blockhouse measurements, monitored during these five flights, were within established redline values or were sufficiently close to specified values to proceed with each launch on schedule.

The Saturn vehicles have a relatively low liftoff acceleration, and exhaust flame and jets impinge on the launch pad until the vehicle reaches approximately 305 feet in altitude. It took 10.7 seconds for SA-5 to reach this altitude after ignition. The pad exposure time of SA-5 was comparable with three Block I vehicles; SA-3 carried a full propellant load with the $165 \mathrm{~K} \mathrm{H}-1$ engines and required approximately 30 percent longer time than the other four vehicles. No excessive pad damage was sustained by any of the Saturn launches.

Results from acoustic measurements taken to predict and control noise generation in the vicinity of the launch area are shown in Figure 9. The band shown in the figure represents far-field measurements taken from all five Saturn launches to a distance of 15 miles from the particular launch pad used.

As shown in Figure 9, free sound field conditions and inverse square law attenuation are not exactly followed by the first five Saturn flights. Atmospheric heterogeneitles and other diffusion effects have a considerable effect on measured values. Sample spectral distribution for three distances from the pad are shown in the lower portion of Figure 9 .

Trajectory - The actual trajectory is basic to the solution of many evaluation problems. Figure 10 shows the postflight trajectory profile for SA-5 in comparison with a typical Block I trajectory profile. Impact of the first stage and eight ejected camera capsules happened approximately $500 \mathrm{~nm}$ downrange, close to predicted. The Block I vehicles were not separated after outboard engine cutoff and only had dummy upper stages.

Saturn vehicles $\mathrm{SA}-1$ and $\mathrm{SA}-4$ re-entered the atmosphere where they were destroyed by aerodynamic forces at 12.4 and 16.8 miles altitude, respectively. SA-2 and SA-3 were destroyed at respective altitudes of 65 to 104 statute miles for the scientific experiment of ejecting water at high altitudes (Project Highwater).

The trajectory of SA-5 was shaped by using a cam device properly constructed to include a predetermined tilt program. This program included a statistically determined wind bias during the first stage flight minimizing the expected angle of attack.

The longitudinal acceleration, force to mass ratio, of $\mathrm{SA}-5$ is shown in Figure 11. The longitudinal loads imparted upon the vehicle follow the same pattern. The longitudinal acceleration reaches a maximum of approximately $6 \mathrm{~g}^{\prime} \mathrm{s}$ when inboard engine thrust starts to decay after inboard engine cutoff signal is given by propellant level sensors.

After inboard engine thrust decay, the longitudinal acceleration maintains approximately half the previous maximum value being sustained by the outboard engines until outboard engine cutoff. The deceleration produced by four retro rockets firing on the $S-I$ stage is also shown in the acceleration profile. The dashed portion of the figure shows the longitudinal acceleration during S-IV stage burn time that begins at an initial acceleration imparted to the flight stage by firing four ullage rockets used to seat the S-IV propellants. The relative acceleration between the two stages at separation is $1.2 \mathrm{~g}^{\prime} \mathrm{s}$.

Propulsion - The main characteristics of the propulsion system are thrust, mass loss per second, and their ratio, the specific impulse. Flight results for these parameters are shown in Figure 12 where a combination of static test results and engine manufacturer gain tables were used to formulate predictions.

The percent deviations from predicted refer to average values over the total flight time. Nominal specific impulse for the S-I and S-IV are $256 \mathrm{sec}$ (sea level) and $429 \mathrm{sec}$ (vacuum) respectively. Block I results are shown for comparison. The largest thrust deviation that is shown occurred on SA-4, with the average total thrust being approximately 1.7 percent higher than predicted.

The deviations in S-I vehicle specific impulse that are shown in Figure 12 were consistently higher than the predicted average value for all Block I flights. Consequently, on the basis of Block I results, the flight predicted specific impulse was increased for $\mathrm{SA}-5$, and as shown, compared very favoribly with flight data from the uprated 188,000 pound thrust $\mathrm{H}-\mathrm{l}$ engines flown on SA-5.

On SA-5, average thrust and specific impulse for the six RL10A-3 engines of the S-IV stage were within less than one percent of predicted.

A relatively important question for engine clusters is the engine-to-engine variation, or cluster dispersion. Iarge differences in thrust, for instance, could yield undesirable disturbance moments or an uneven propellant consumption even though the vehicle design tends to minimize such effects. Figure 13 shows the one sigma thrust deviation of all engines flown thus far from their respective mean values. As expected, this dispersion is larger than the deviation of the total vehicle thrust from predicted (Figure 12). 
The propellant utilization was systematically improved for each successive flight of the Saturn I's. To illustrate this, the ratio of the prope1lants consumed to the predicted usable propellants yield the following percentages for each of the five flights:

$\begin{array}{ll}\text { SA-1 } & 98.1 \text { percent } \\ \text { SA-2 } & 98.7 \text { percent } \\ \text { SA-3 } & 99.35 \text { percent } \\ \text { SA-4 } & 99.8 \text { percent } \\ \text { SA-5 } & 99.87 \text { percent }\end{array}$

The reasons for this steady increase in propellant utilization is primarily a result of information received during flight test of each vehicle. For instance, SA-3 and SA-4 used LOX depletion cutoff and thereby reduced the amount of propellant left onboard. Before using this type of cutoff, SA-1 and SA-2 were used to study the effects of acceleration on propellants in the tanks in order to assign a level at which SA-3 and SA-4 could be cut off by depletion.

After Block $I$, the SA-5 tanks were elongated for the uprated $\mathrm{H}-1$ engines and held 850,000 pounds of usable propellants instead of 750,000 1bs. A1so, the propellant feed lines were modified for SA-5 and resulted in better utilization of the propellants.

The propellant utilization of the S-IV stage was 99.95 percent of usable loaded propellants. This highly satisfactory degree of utilization was accomplished by controlling the engine mixture ratio with an active propellant utilization system throughout flight.

Shown in Figure 14 are the predicted, actual, and principally unusable propellant residuals, at stage cutoff, for each of the five flights. The residuals are also expressed in percent of total propellant load. In comparing the percentage of total propellant remaining with the amount loaded on $\mathrm{SA}-3$ and $\mathrm{SA}-4,1.9$ and 2.2 percent respectively, SA-3 had more usable propellants left in the tanks than SA-4 but the percentage was less because SA-3 carried a full propellant load of $850,000 \mathrm{lb}$.

Control - Attitude stabilization of the SA-5 vehicle was obtained through the use of error signals from a gyro stablized platform and body fixed accelerometers. The sensors were located in the Instrument Unit. The accelerometers were only active between 25 and 90 seconds flight time and had their maximum gain in the $35,000 \mathrm{ft}$ altitude region where the highest winds occur and the region of high dynamic pressure.

The rigid body was stabilized by differentiation of the attitude error signal; also in the attitude channel, the elastic body modes below $3 \mathrm{cps}$ were phase stabilized while the higher modes were gain stabilized. Phase stabilization was accomplished by establishing a minimum phase lag in the shaping network at $3 \mathrm{cps}$. All modes in the accelerometer channel were gain stabilized. Elastic body data used for control system design were obtained from full scale dynamic tests.

Lateral load torques caused by winds (especially during high $Q$ region) were reduced considerably by a wind biased tilt program on SA-4 and SA-5. (The first two flights utilized a tilt program based on 7 engines operating in order to minimize control requirements in the event of an engine failure; $\mathrm{SA}-3, \mathrm{SA}-4$, and $\mathrm{SA}-5$ were based on 8 engine tilt program.) The winds were higher on SA-4 than those previously encountered, but due to the tilt bias, control angles in the pitch plane were reduced considerably. The winds encountered by SA- 5 were somewhat less than the maximum observed in the other flights, resulting in very small control angles during the critical high dynamic pressure region.

Figure 15 shows the maximum wind envelope obtained from Block I flights together with those encountered on SA-5. A 95 percent probability wind speed envelope used for design purposes is also shown. Resulting maximum angles-of-attack are shown in the upper portion of the figure.

The majority of first stage actuator. deflections are in response to forcing functions primarily caused by random wind and propellant sloshing. On al1 Saturn I flights, the maximum actuator deflections occurred in the high dynamic pressure region; these values are shown in Figure 16. With the exception of SA-4 and SA-5 (both vehicles had wind biased tilt programs) all maximum deflections were in the pitch plane.

The actuators are designed for a maximum deflection of 8 degrees; fins on SA-5 add stability; a wind biased tilt program reduces pitch plane control parameters. These factors, plus the fact that $S A-5$ was flown near drift minimum control, reduced the control angles on SA-5 to small values. The design limit considers a combination of wind gusts, embedded gusts, variations in mass, thrust, and aerodynamic characteristics, and the possibility of one engine-out.

Because of the sma1l actuator deflections and the angles-of-attack encountered on SA-5 the vehicle bending moment was generally. small. Figure 17 shows the maximum bending moment observed during booster. flight of SA-5 in comparison with the Block I average.

S-IV stage engine deflections on SA-5 were maintained to essentially zero as would be expected for a near vacuum flight. Some propellant sloshing disturbances were present during S-IV flight but are not considered a problem.

Propellant sloshing has presented no detrimental problem on any of the Saturn flights, although sloshing instability was present to varying degrees on all vehicles during the latter portion of flight. When the liquid surface went below the S-I stage baffles, damping provided by the smooth walls was insufficient to prevent a small buildup in sloshing amplitude. Sloshing instability was most pronounced on SA-1.

After SA-1, additional accordion baffles were installed between the last three ring frames in the fuel tanks, and between the last four ring frames in the 70 inch LoX tanks. The new baffle arrangement, included in Block II vehicle plus additional baffles in the upper portion of the elongated tanks, decreased the time available for build-up of oscillations. This is demonstrated in Figure 18 where a digital filter was used to separate the sloshing response of the actuators from the telemetered actuator positions. The maximum 
actuator response to sloshing was approximately 2 degrees on SA-1.

In the latter portion of S-I flight of SA-5, the observed actuator deflections from sloshing were again very sma11, indicating satisfactory anti-slosh baffle arrangement for Block II vehicles. The maximum slosh amplitude that occurred during booster flight of SA-5 occurred during the high dynamic pressure region. During this time, about 0.8 degree of yaw actuator deflection resulted from first mode sloshing.

The S-IV LOX tank contains baffles in the upper portion of the tank to suppress sloshing during booster flight and the early portion of S-IV flight. Maximum sloshing observed on SA-5, S-IV flight, occurred just after separation and during the early portion of second stage flight. Damping after the first few seconds of S-IV burn was very near the predicted value of 3 percent, indicating the baffle arrangement performed as expected.

Separation - The separation systems operated properly and the S-IV stage was separated from the S-I stage with no indication of interference between stages; however, the angular rates in all three planes shown in Figure 19 increased for both stages during separation. Some of the sources for torques acting on the S.-IV stage are:

a. Unsymmetrical arrangement of the three $\mathrm{LH}_{2}$ chilldown exhausts.

b. U1lage motor misalignments and/or thrust variations.

\section{c. Center of gravity offset.}

d. Uneven thrust buildup of S-IV engines.

Analog computations resulted in duplicating the observed motion with a reasonable combination of above mentioned torques. The oscillatory motion in the roll plane resulted from sloshing in the pitch plane coupling into the roll plane due to a lateral. C.G. shift.

Much larger rates were observed on the S-I stage than were experienced by the $S-I V$ stage during the separation process (see Figure 19). The rates can be simulated by using a combination of a C.G. Offset; a. Retro motor thrust misalignment and/or thrust variations; $S-I$ stage engine deflections and thrust variations during thrust decay; LOX venting.

As seen in Figure 19, the second stage was ignited $1.7 \mathrm{sec}$ after separation signal. The two stages had completely disengaged by moving $12 \mathrm{ft}$ or at $1.1 \mathrm{sec}$ after separation.

Aerodynamics - Figure 20 shows the gradient of the normal force coefficient $\left(C_{z}{ }^{\prime}\right)$ and the center of pressure location (CP/D) from telemetered values of angle-of-attack, normal acceleration, and engine deflection. Data are shown for SA-1 and SA-2; the angle-of-attack on SA-3, SA-4, and SA-5 trajectories were too smal1 to yield accurate results. Good agreement with predictions from wind tunnel test was achieved.
The axial force coefficient shown in Figure 21 relates both $\mathrm{SA}-5$ and Block I results together with predicted wind tunnel results. The axial force coefficient was determined from flight data by considering the vehicle propellant consumption (mass loss), thrust, and flight trajectory. Actual values are somewhat lower than predicted. The higher coefficient of SA-5 is primarily due to the fins.

The SA-5 flight exhibited a small but noticeable roll moment increasing gradually with flight time, in a CCW direction (viewed from the rear). A maximum attitude of 3.3 degrees was reached at 56.4 seconds. After 60 seconds, the roll attitude decreased rapidly and remained near zero from 68 seconds to the end of booster flight. A maximum actuator deflection of 0.4 degree was required in pitch and yaw to equalize the torque causing this rol1 moment.

Figure 22 shows the roll moment calculated from the engine deflections. The peak moment was approximately 780,000 in-1b. This roll moment is associated with the unsymmetry in the arrangement of the four turbine exhaust duct fairings and their relative position to the four shrouds shown at the top of Figure 22. Wind tunne1 tests confirmed the existence of the roll moment. However, the magnitude of the moment, according to the wind tunnel test, should be two times higher than actually observed. The exact mechanism of this phenomenon is not yet known.

Instrumentation - A review of Block I and SA-5 instrumentation performance is shown in Figure 23 . The average instrumentation performance for the five flights was 97.5 percent. Measurements are identified as failures when approximately 50 percent or more of the data was unusable.

Overall reliability of the SA-5 measuring system was 97.4 percent. There were 30 failures that resulted in total loss of information. Data acquired was of excellent quality. A11 telemetry stations received a sufficient signal except during retro rocket firing at separation. The signal attenuation experienced during this period was much greater than attenuation during retro firing on SA-3 or SA-4 possibly due to mixing of the exhaust jets from both retro and ullage rockets.

Two airborne tape recorders were utilized on SA-5 to record data during periods of high RF attenuation. Operation of both recorders was satisfactory and data contained in the playback records were of good quality.

An onboard TV system on SA-5 transmitted good quality pictures back from the S-I stage from liftoff until after separation.

Seven out of eight onboard movie cameras operated satisfactorily and were recovered successfully by the AMR. The windows of the four cameras mounted outside the vehicle were increasingly obscured during flight due to depositing of thermal protective coating materia1. A purge system will be installed on the next flights. 


\section{4.c. Vehicle Environment}

Bending - Figure 24 shows the results of a band pass digital filter used to extract first mode vehicle bending data from normal accelerometer measurements. The amplitude of the bending oscillations refers to the vehicle nose where they are at their maximum.

A predominant bending frequency was observed on SA-3 and SA-4 after cutoff, resulting from a forced response with low damping caused by engine gimballing during and after thrust decay. This did not occur on SA-5 due to a change in the control gains.

The maximum first mode bending amplitude observed on SA-5 and shown in Figure 24 was less than half the magnitude observed on Block I vehicles.

The lower portion of Figure 24 shows the observed bending frequencies from SA-5 flight test data compared to dynamic test results. The slight increase in frequency with time is due to the loss of propellants. The band of frequencies shown represents bending frequencies observed on Block I flights, all of which fell around Block I dynamic test results.

Generally speaking, the component vibration levels observed on SA-5 were approximately the same as those observed on Block I flights. There were two exceptions. Engine vibrations were higher on SA-5 due to the higher thrust engines, and instrument unit vibrations were lower due to their relocation above the S-IV stage (instrument canisters on top of the first stage were used on Block I).

The bottom of Figure 25 shows the engine component vibrations, and on the top the structures vibration levels in the form of two envelopes representing Block $I$ and $S A-5$ respectively. There are three basic regimes during flight: the high vibration levels at liftoff generated by the engines (mechanical source) and reflected to the vehicle from the ground (acoustical source), then the high dynamic pressure area at about $40 \%$ flight time where aerodynamic sources greatly contribute to the vibration level, and finally, the vibration due to cutoff shocks caused by the severe transients in vehicle thrust.

For the great majority of individual measurements the level at liftoff is by far the highest. It is comparable to the levels experienced during captive firings. In no case did any of the vibration levels exceed Saturn design tolerance values. The frequencies inserted give approximate values of the major characteristic frequencles resulting from spectral analysis.

Heating - Temperatures measured during flight of SA-5 were within anticipated values. The measured surface temperatures were somewhat lower than predicted due to a slight deviation of the actual trajectory.

The base thermal environment is determined by a complex interplay of radiation and convection, both factors varying with altitude of flight and also varying as a function of the location on the vehicle base.
Figure 26 shows two of the parameters of interest. The total flux is shown for a representative group of measuring points on the large heat shield area; the flux is also shown for a single calorimeter measurement on the center star region, the flame shield. For comparison, predictions are shown. These predictions, to be used for the heat protection design, were purposely conservative and were primarily based on both wind tunnel base heating tests performed in the NASA Lewis Research Center and full scale single engine static tests.

For most of the heat shield area the radiation heat flux measured was higher than the total flux shown in Figure 26, indicating the existence of convective cooling. This conclusion was substantiated by comparing the gas temperatures at different distances from the heat shield surface.

The highest gas temperatures were measured on the flame shield with a peak at approximately $25,000 \mathrm{ft}$ altitude. SA-5 reached a peak of $3,2000^{\circ} \mathrm{F}$. Thereafter, the flame shield temperature decreases slightly and maintains a rather constant equilibrium value of $2,800^{\circ} \mathrm{F}$. Block I flights showed a very similar behavior.

The average heat shield temperatures reached a peak of $1,500^{\circ} \mathrm{F}$ around $75,000 \mathrm{ft}$ altitude.

\section{4.d. Vehicle Modifications}

As a consequence of the experience and findings of the first five Saturn I flight tests, several design changes were implemented (Table 5). Some of these changes were pre-planned as part of the development program and had to wait only for quantitative flight results prior to actual implementation. This category includes accelerometer control and S-I depletion cutoff. Another group included in Table 5 are changes due to unexpected occurrences or recognized design deficiencies, e.g. the sloshing instability observed in the first flight, or the aerodynamic roll moment observed on SA-5. A third category includes systematic deviations from the level of predicted performance which occur because of incomplete simulation of actual flight conditions in preflight tests and calculations. A good example for this group is the first stage propulsion system performance which turned out to be consistently about one percent higher than originally predicted.

of course, Table 5 does not show all the modifications which have actually been made; it is rather a list of typical examples. However, it is correct to state that, up to this point, no major unexpected design change had to be initiated on the basis of flight test - thus proving the design maturity of the Saturn I vehicle.

\section{Acknowledgement}

The assistance of Mr. James R. Martin in preparing material for this paper is gratefully acknowledged. 


\section{Bibliography}

1. MSFC MPR-SAT-WF-61-8 (C), Saturn SA-I F1ight Evaluation, Saturn Flight Evaluation Working Group, December 14, 1961.

2. MSFC MPR-SAT-WF-62-5 (C), Saturn SA-2 Flight Evaluation, Saturn Flight Evaluation Working Group, June 5, 1962.

3. MSFC MPR-SAT-63-1 (C), Saturn SA-3 Flight Evaluation Volume I, Saturn Flight Evaluation Working Group, January 8, 1963.

4. MSFC MPR-SAT-63-6 (C), Results of the Fourth Saturn I Launch Vehicle Test Flight, Saturn Flight Evaluation Working Group, May 10, 1963.

5. MSFC MPR-SAT-FE-64-15 (C), Results of the Fifth Saturn I Launch Vehicle Test Flight, Saturn F1ight Evaluation Working Group, Apri1 1, 1964.
6. KSC-TR-46-1 (U), Preliminary Results of Sound Pressure Level Measurements During SA-5 Launch, R. L. Wilkinson, February 6, 1964.

7. MSFC R-P\&VE-VSA-63-181 (U); SA-5 Saturn I Block II Vehicle Description, Assembly Engineering Section, December 26, 1963.

8. MSFC MPR-SAT-63-9 (C), Results of Saturn I. Block I Launch Vehicle Flight Tests,

J. R. Martin and C. R. Lindle, June 26, 1963.

Most of these reports can be made available to qualified organizations upon request if requirements for obtaining classified information are met. Requests should be addressed to:

Director, George C. Marshall Space F1ight Center Huntsville, Alabama

Attention: Chairman, Saturn Flight Evaluation Working Group, R-AERO-F

Table 1

Saturn I Data

Vehicle

Weight at Liftoff (lb)

Weight at lst Stage Cutoff (lb)

Weight at 2nd Stage Ignition (lb)

Weight at 2nd Stage Cutoff (lb)

Total Number of Measurements

lst Stage

Propellant Weight (lb)

Propellant Flow Rate (lb/s)

Engines

Total Thrust (Sea Level) (lb)

Initial Acceleration (g)

2nd Stage

Propellant Weight (lb)

Propellant Flow Rate (1b/s)

Engines

Total Thrust (Vacuum) (lb)

Initial Acceleration (g) S. L., Full Thrust

$$
\begin{array}{r}
1.13 \cdot 10^{6} \\
270,000 \\
138,000 \\
38,300 \\
1,180
\end{array}
$$

. 9 .

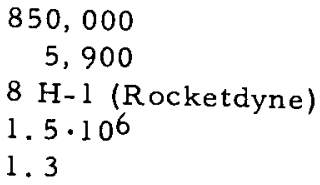

100,000

6 RL10-A3 (P\&W)

90,000

0.6 
Saturn I Teat Objectives

\begin{tabular}{|c|c|c|c|c|c|}
\hline FLIGHT & $5 A-1$ & SA-2 & $S A-3$ & SA-4 & SA -5 \\
\hline $\begin{array}{l}\text { LAUNCH } \\
\text { DATE }\end{array}$ & oct. 27, 61 & Apr. 25,62 & Nov. 16,62 & Mar. 28, 63 & Jan. 29,64 \\
\hline $\begin{array}{l}\text { PRIMARY } \\
\text { MISSIONS }\end{array}$ & \multicolumn{4}{|c|}{$\begin{array}{l}\text { (1) S-1 Propulsion Syetem (165 K) } \\
\text { (2) Vehicle Structuret } \\
\text { (3) Vehiele Control } \\
\text { (4) Vehicle Dynanics } \\
\text { (5) Vehicle - Launch Facility Compatability }\end{array}$} & $\begin{array}{l}\text { (1) S-1 Propultion (18B K) } \\
\text { (2) Separation } \\
\text { (3) Live S-IV Stago } \\
\text { (4) Intrument Unit }\end{array}$ \\
\hline $\begin{array}{l}\text { SECONDARY } \\
\text { MISSIONS }\end{array}$ & & Highwater I & $\begin{array}{l}\text { Highwater I } \\
\text { Depletion Curofi } \\
\text { Retro Rockets } \\
\text { Urnbilical Swing Arm } \\
\text { Now Heat Protection } \\
\text { Guidance Pansenger } \\
\text { Full Propellent Losding }\end{array}$ & $\begin{array}{l}\text { Aecelerometer Control } \\
\text { Depletion Cutoff } \\
\text { Retro Rockets } \\
\text { Umbilieal Swing Arm } \\
\text { New Heat Protection } \\
\text { Guldance Pasenger } \\
\text { Single Engine Out } \\
\text { Blk II Aerodynamic Simula tion } \\
\text { Now Antengs Syotem }\end{array}$ & $\begin{array}{l}\text { Aerodyanmic Stability } \\
\text { Hydrogen Venting } \\
\text { New Launchez } \\
\text { Payload Capebility 18,000 ib } \\
\text { Orbit Decay } \\
\text { Gujdance Pasuenger }\end{array}$ \\
\hline
\end{tabular}

Table 3

1. Stage Structural Tests

2. Engine Testing

a. Rocketdyne (H-I)

b. MSFC $(\mathrm{H}+1)$ Verification

c. Pratt \& Whitney (RL/OA-3)

d. MSFC (RLIOA-3) Verification

3. Stage Electrical Systems and Subsystems Tests

4. Instrumentation Systems and Subsystems Tests

5. Range Safety Equipment Tests
6. Ground Support Equipment Tests

7. Vehicle Static Firing Tests (Full Scale Test Vehicle Stages)

a. S-I All Systems (SA-T)

b. S-IV Battleship

c. S-IV All Systems

8. Instrument Unit Vibration Tests

9. Dynamic Test (Full Scale)

a. First Stage Configuration b. Second Stage Configuration

\section{Acceptance Tests}

1. Stage Pre-Static Tests

a. Pressure Tests

b. Electrical Tests

c. Mechanical Tests

d. Instrumentation Test

4. Cape Kennedy Flight Readiness Acceptance Tests

a. Systems Checkout

b. Propellant Loading Tests

c. Simulated Flight Test

2. Stage Static Firing Testo

3. Stage Post-Static Tests

Pressure Test

b. Electrical Tests

c. Mechanical Test

d. Instrumentation Tests

Table 5

Examples of Saturn I Modifications During R\&D Testing

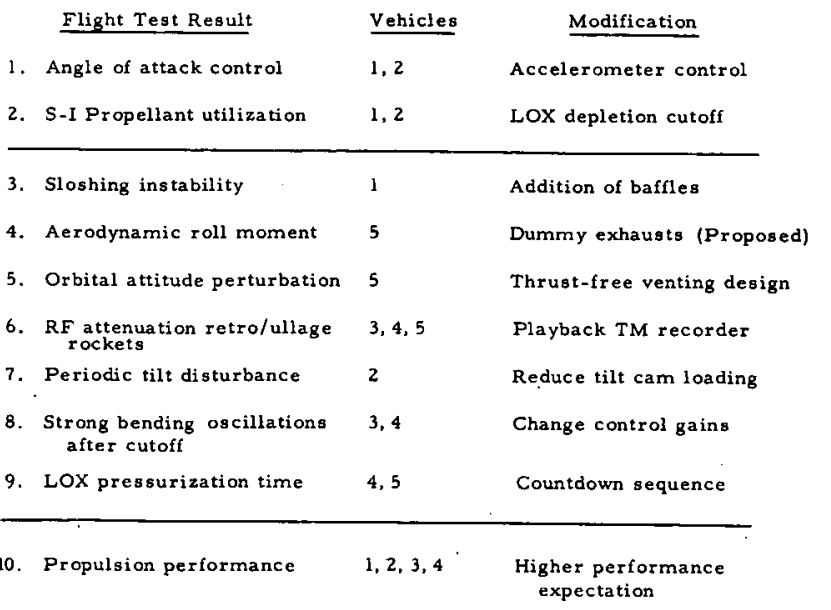

Data Processing Equipment

\begin{tabular}{|c|c|c|c|}
\hline Function & Machine & Machine Houra & Machine Hours \\
\hline Oscillographs & Ground Station & 115 & 440 \\
\hline Digitize & $\begin{array}{l}\text { PCM Station } \\
\text { Microsadic } \\
\text { Raw Cycle Counter } \\
\text { (RCC-3) }\end{array}$ & $\begin{array}{l}70 \\
25\end{array}$ & $\begin{array}{l}75 \\
25\end{array}$ \\
\hline $\begin{array}{l}\text { Input/Output for } \\
7090 / 7094 \text { Prog. }\end{array}$ & IBM 1401 & 55 & 90 \\
\hline $\begin{array}{l}\text { Linearize and } \\
\text { Eval. Prog. }\end{array}$ & $\begin{array}{l}\text { IBM } 7090 / 7094 \\
\text { B- } 5000\end{array}$ & 70 & 444 \\
\hline $\begin{array}{l}\text { Plotter, Microfilm, } \\
\text { Printer }\end{array}$ & $5 C 4020$ & 30 & 52 \\
\hline Tape Plotter & EAI Plotter & 165 & 52 \\
\hline Film Reduction & $\begin{array}{l}\text { Mann Comparator \& } \\
\text { Others }\end{array}$ & 45 & 64 \\
\hline $\begin{array}{l}\text { Spectral Density } \\
\text { and Simulation }\end{array}$ & $\begin{array}{l}\text { Analog Computer } \\
\text { (TPC) }\end{array}$ & & 20 \\
\hline
\end{tabular}
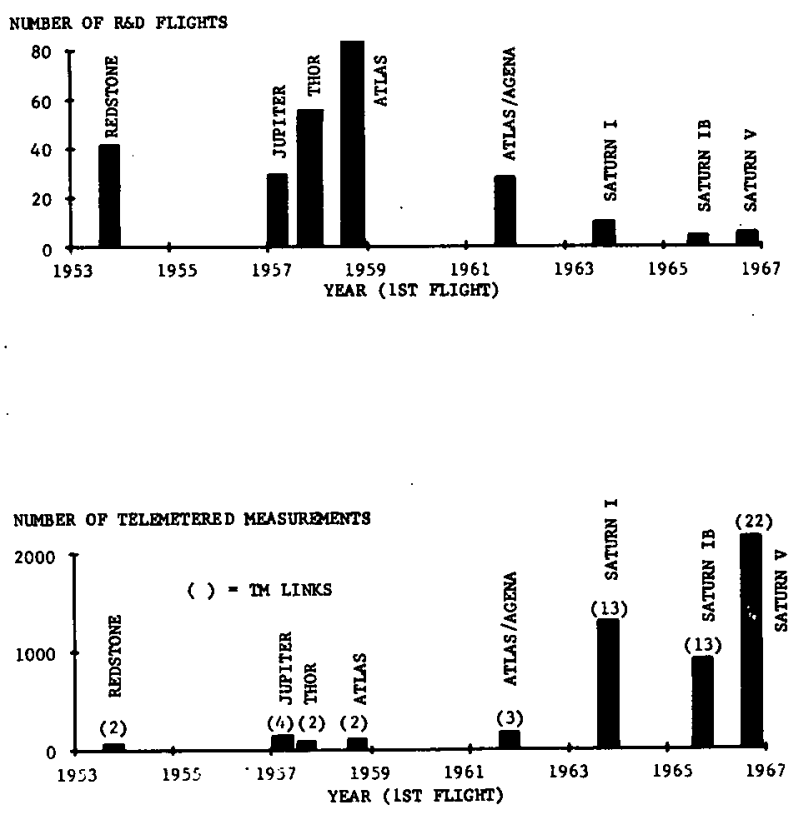

$\cdot 10$ 


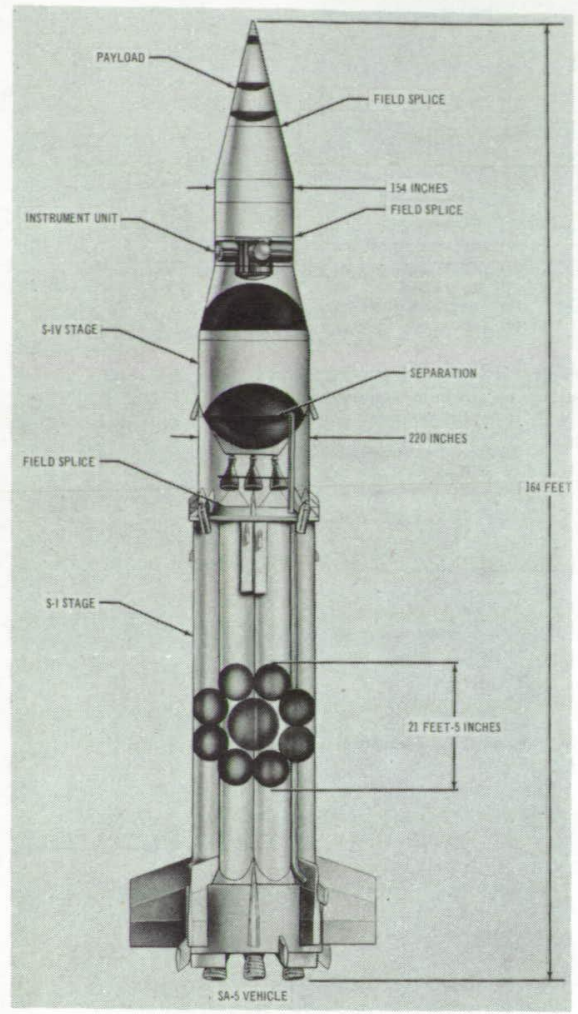

EIGURE. 2 SA-5 CONFIGURATION

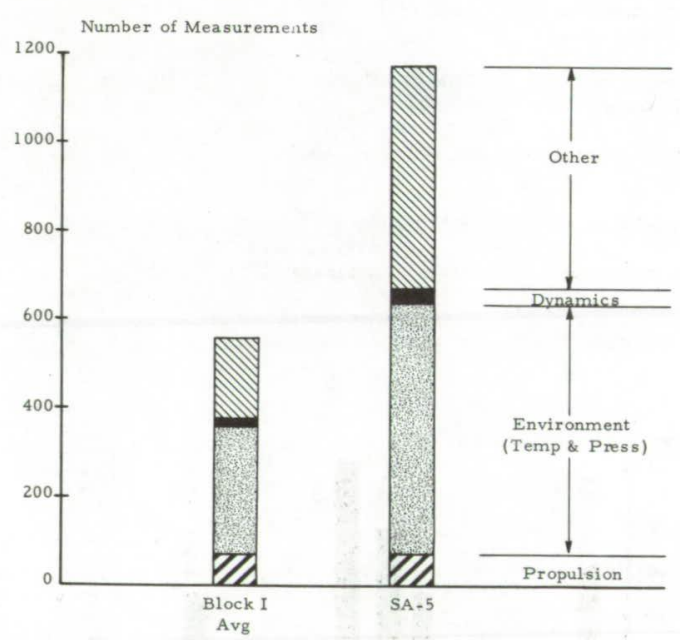

FIGURE 4 INFLIGHT MEASUREMENTS

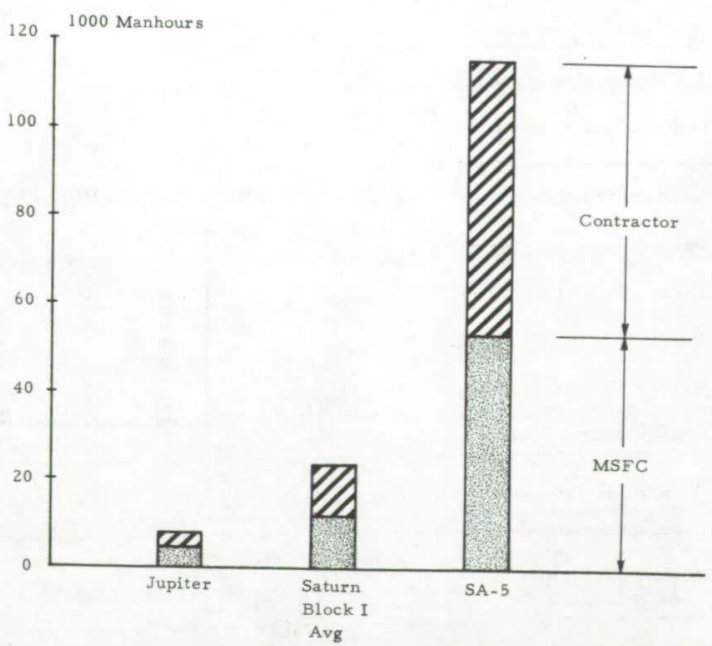

FIGURE 6 MANPOWER FOR FLIGHT EVALUATION 

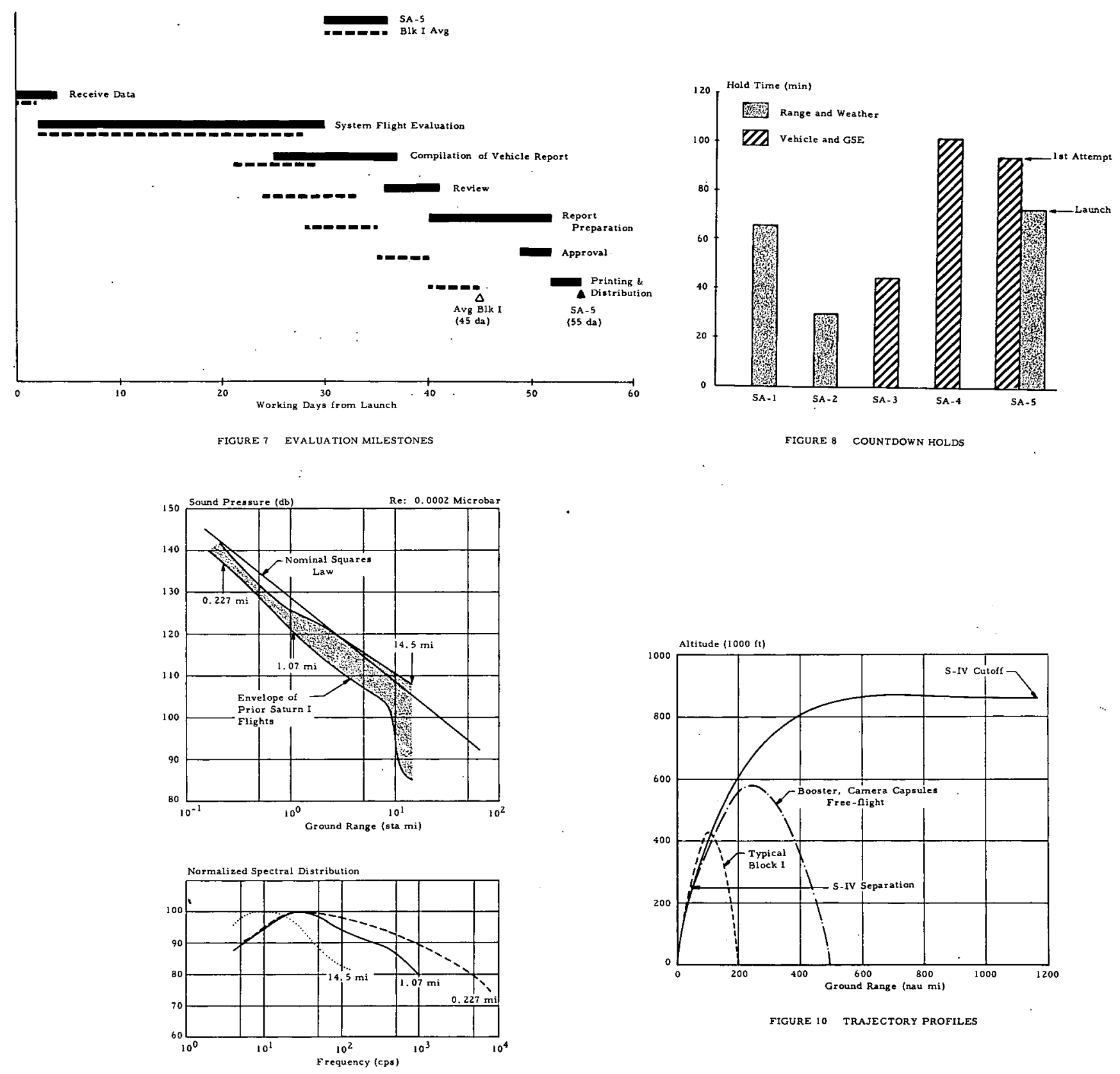

FIGURE 9 SATURN SOUND PRESSURES IN LAUNCH AREA

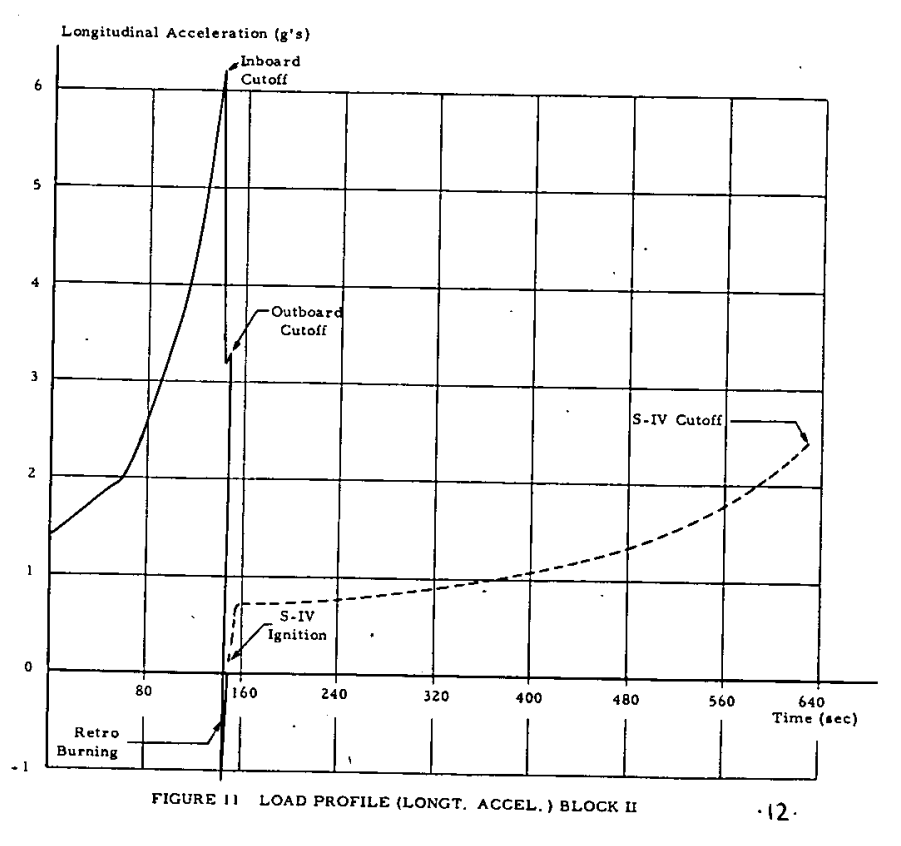



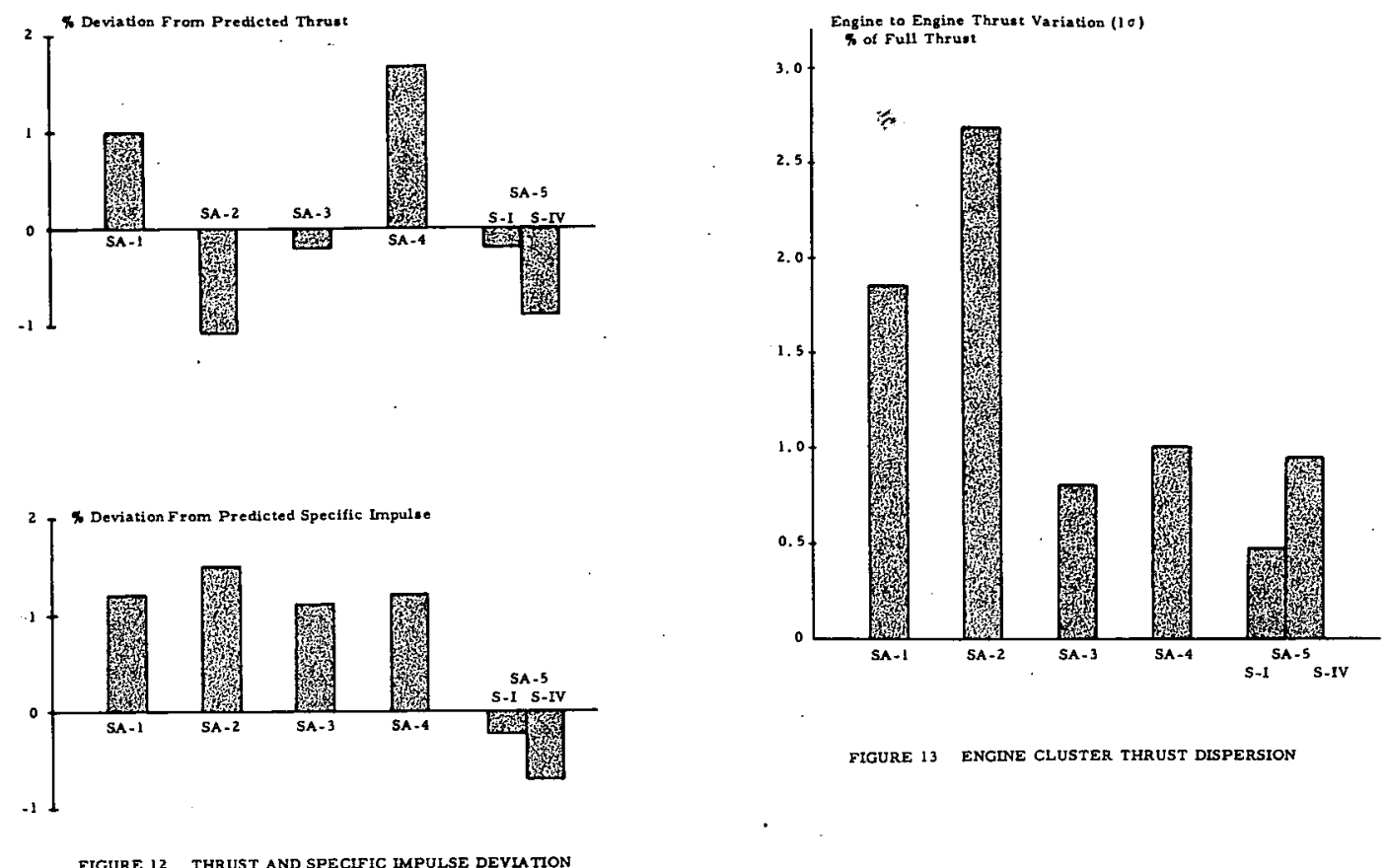

FIGURE 13 ENGINE CLUSTER THRUST DISPERSION

FIGURE 12 THRUST AND SPECIFIC IMPULSE DEVIATION
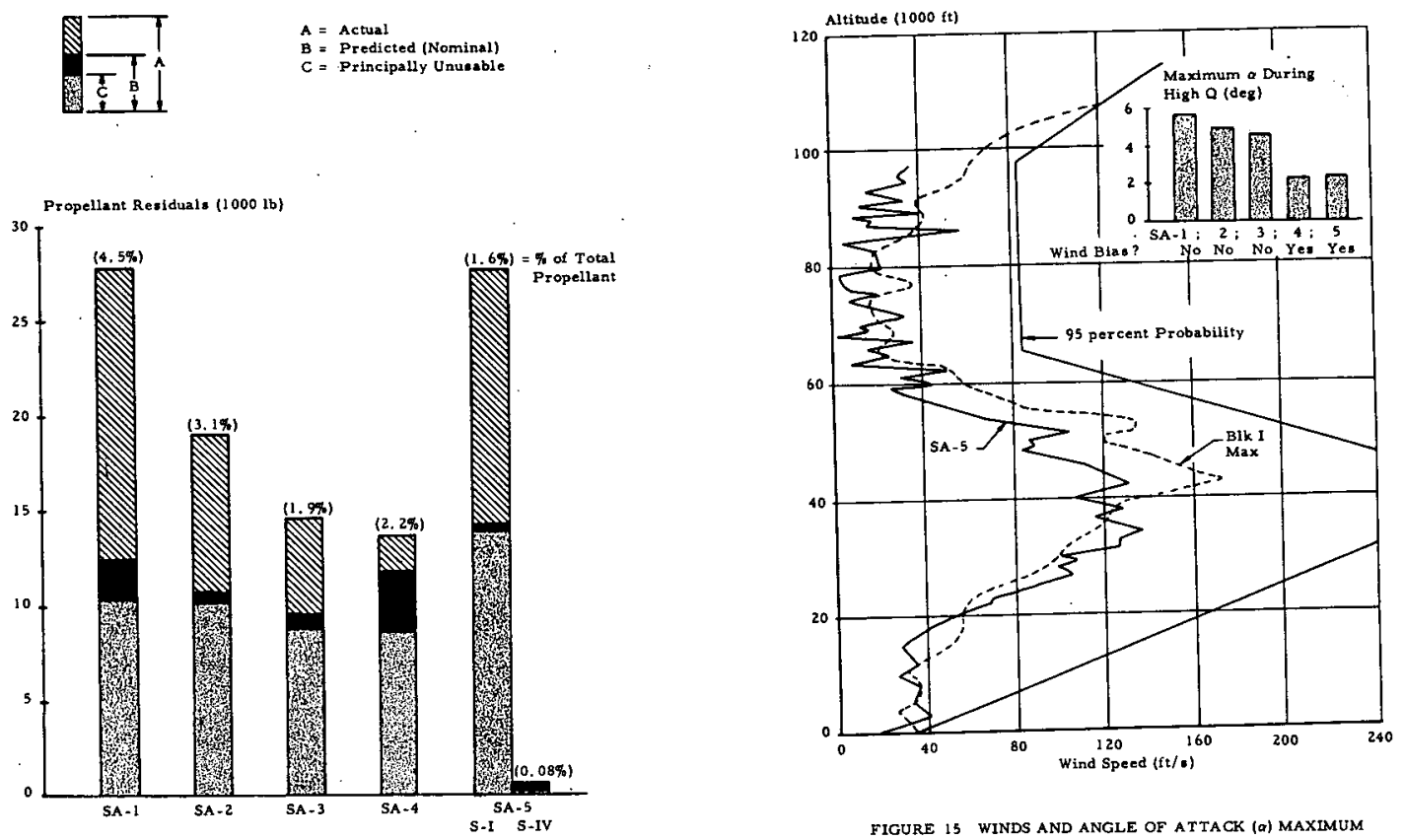

FICURE 14 PROPELLANT RESIDUALS

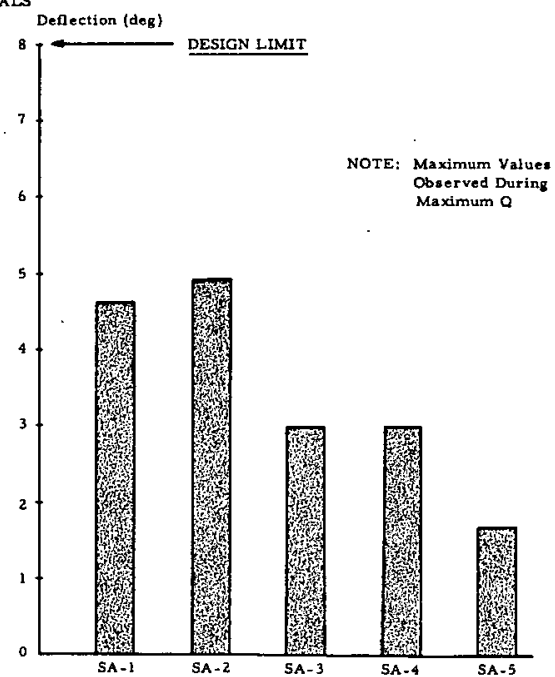



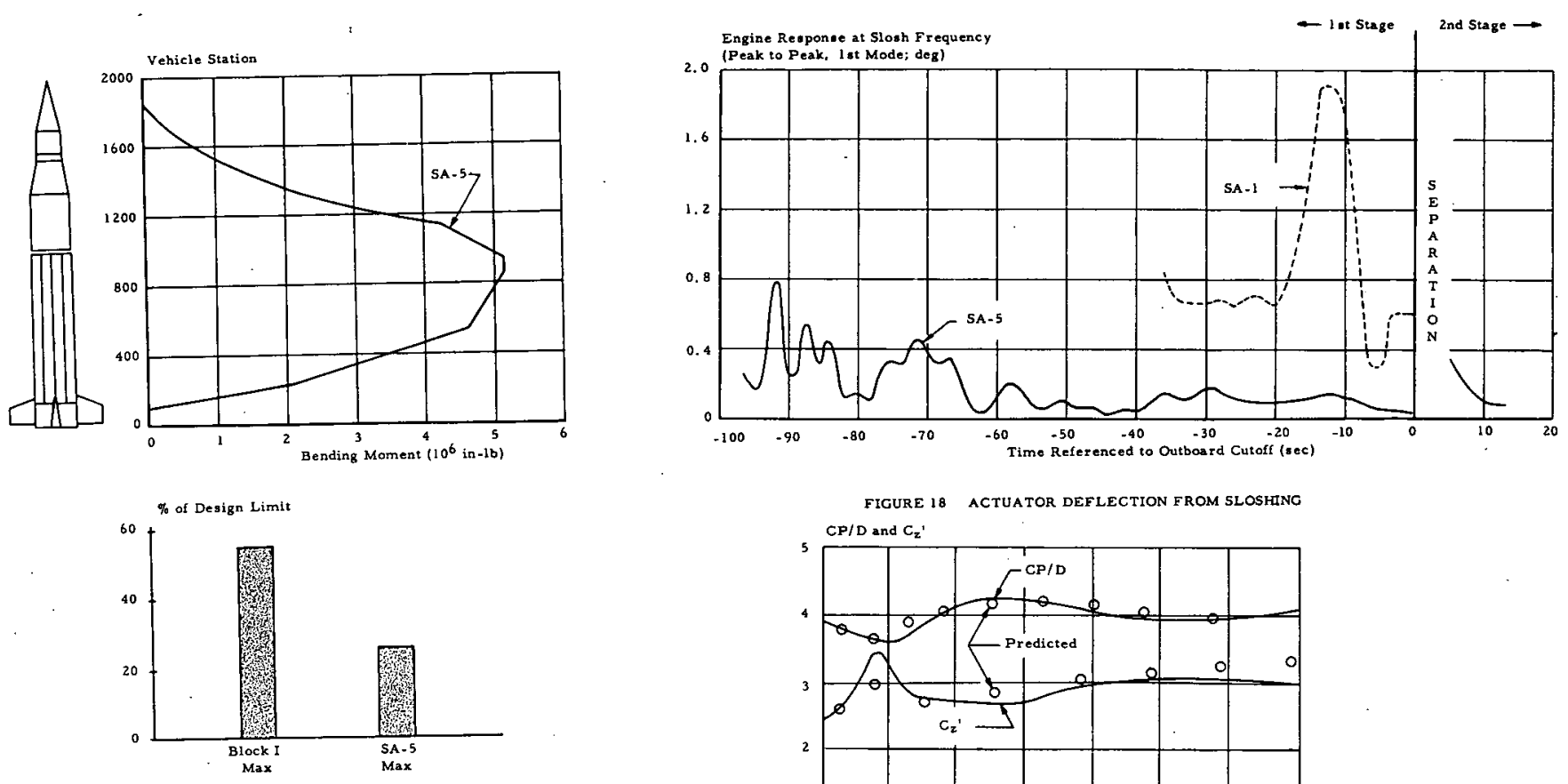

FIGURE 17 MAXIMUM BENDINC MOMENT
(FIRST STAGE)
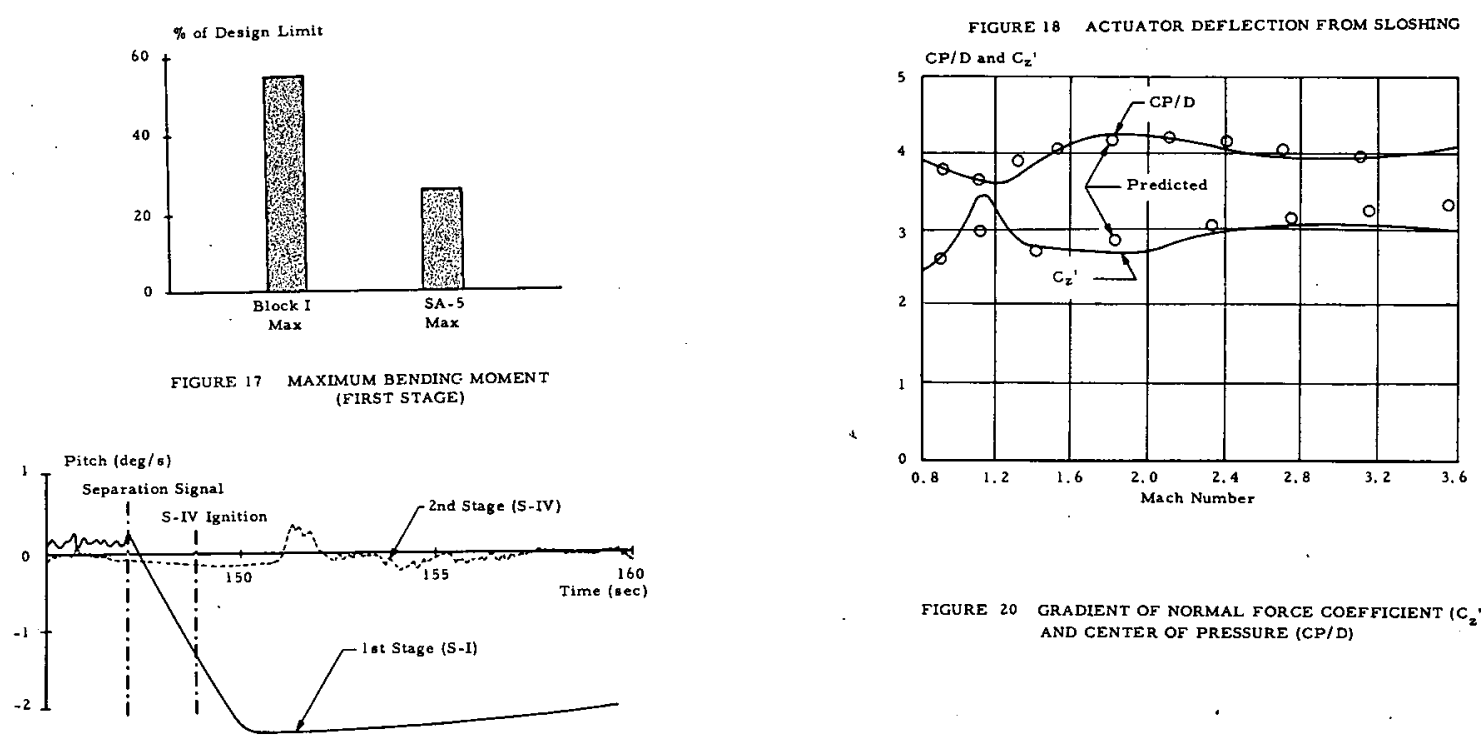

FIGURE 20 GRADIENT OF NORMAL FORCE COEFFICIENT (C $\left.{ }^{\prime}\right)$
AND CENTER OF PRESSURE (CP/D)
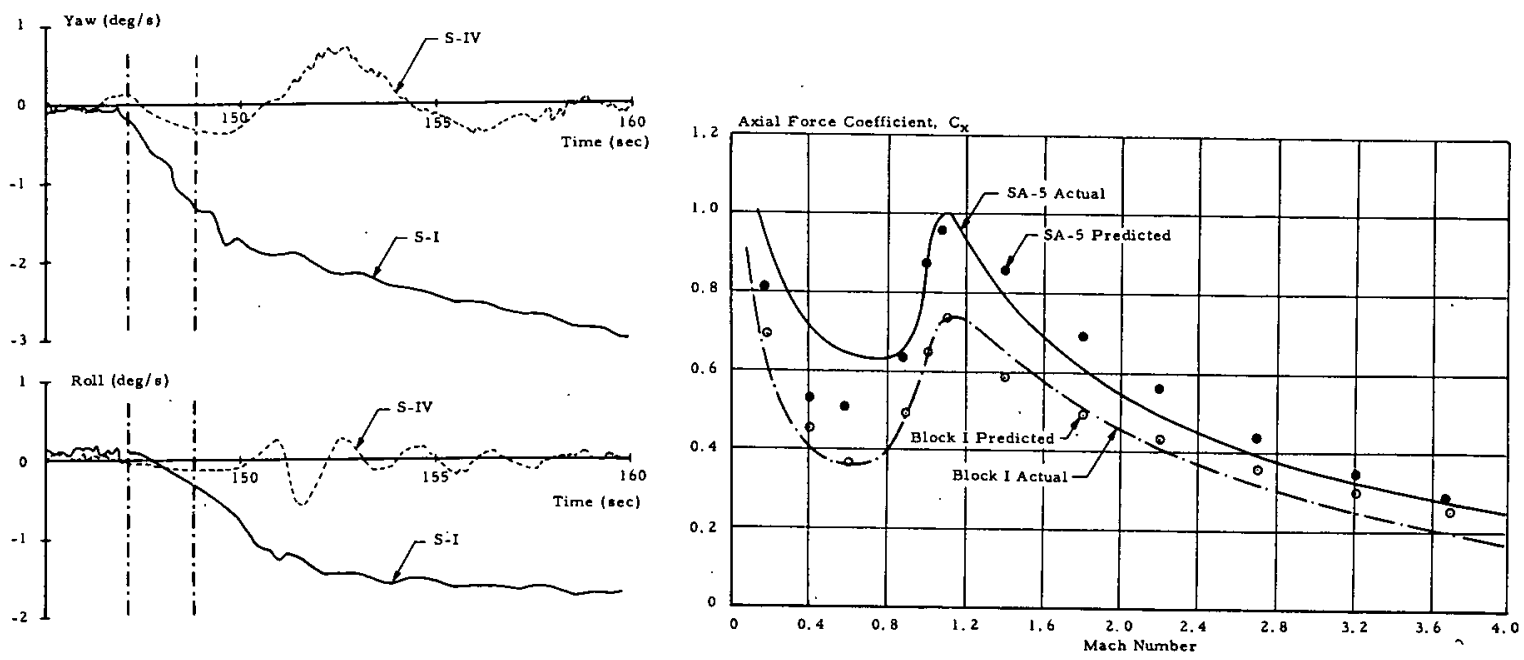

Figure 19 aNGULAR RATES AT SEPARAtion

.14

FIGURE 21 AXIAL FORCE COEFFICIENT 

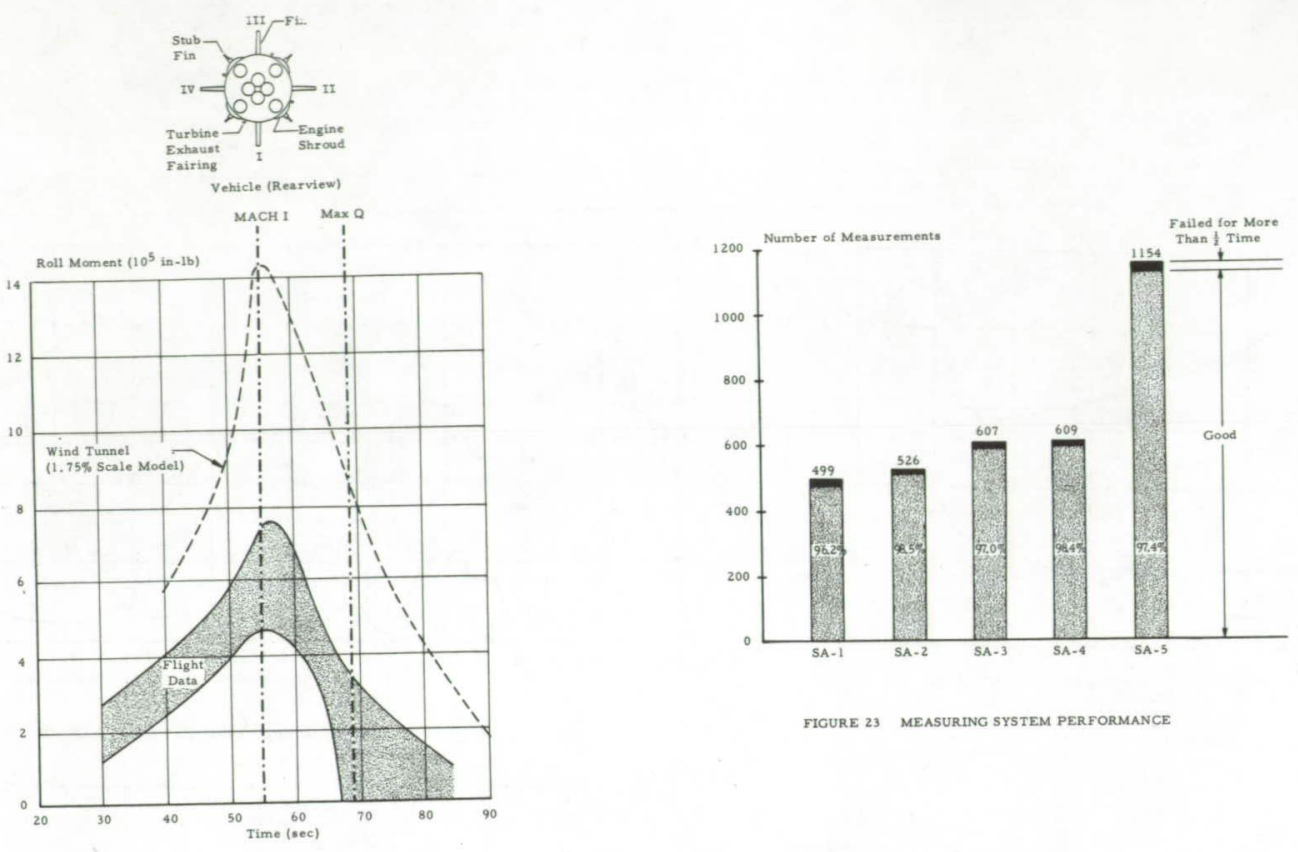

FIGURE 23 MEASURING SYSTEM PERFORMANCE
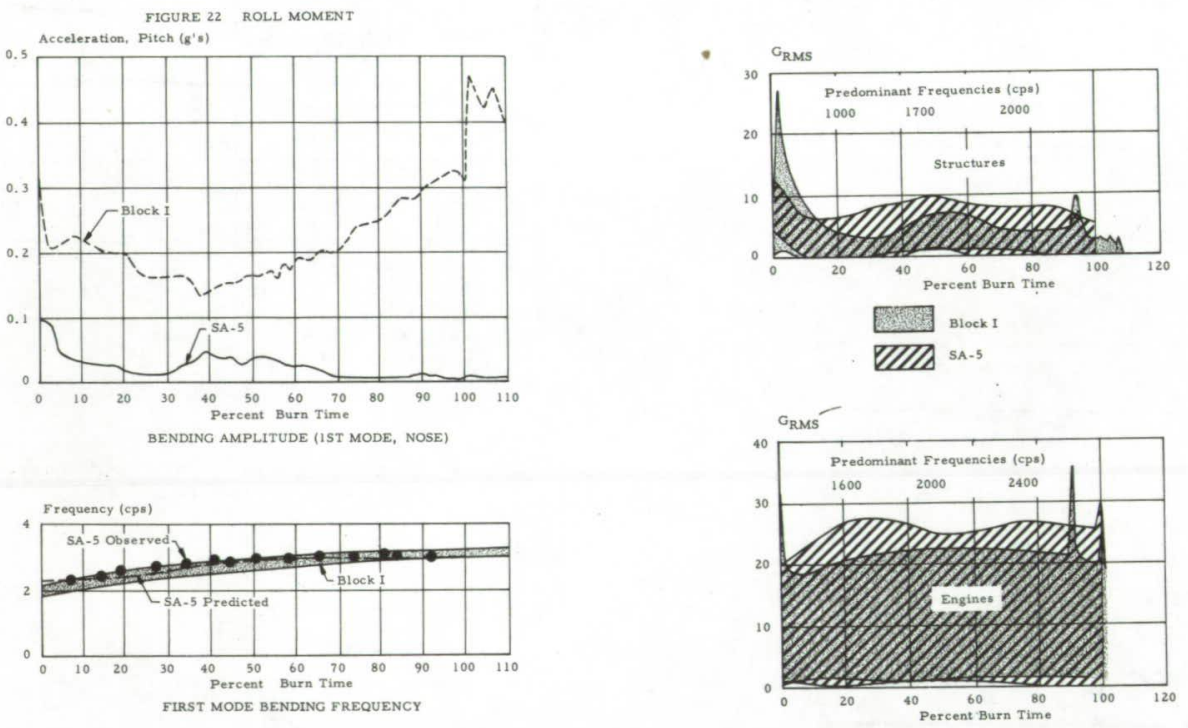

FIGURE 24 BENDING FREQUENCY AND AMPLITUDE ENVELOPE
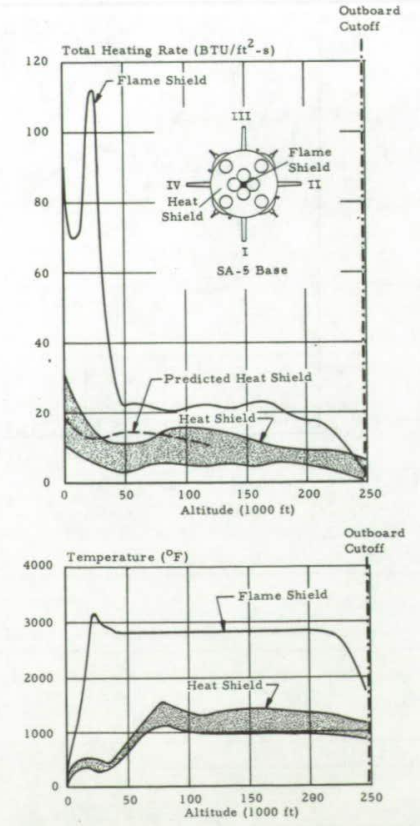